\title{
EBNA1 inhibitors have potent and selective antitumor activity in xenograft models of Epstein-Barr virus-associated gastric cancer
}

\author{
Samantha S. Soldan ${ }^{1}$ - Emma M. Anderson ${ }^{1,3}$. Drew M. Frase ${ }^{1} \cdot$ Yue Zhang $^{1} \cdot$ Lisa B. Caruso $^{1}$ - Yin Wang ${ }^{2}$. \\ Julianna S. Deakyne ${ }^{1,4}$ - Benjamin E. Gewurz ${ }^{2} \cdot$ Italo Tempera $^{1} \cdot$ Paul M. Lieberman ${ }^{1} \cdot$ Troy E. Messick $^{1}$ (1)
}

Received: 23 December 2020 / Accepted: 20 April 2021 / Published online: 30 April 2021

(c) The International Gastric Cancer Association and The Japanese Gastric Cancer Association 2021

\begin{abstract}
Background and aims Epstein-Barr virus (EBV)-associated gastric carcinoma (EBVaGC) is the most common EBV-associated cancer and accounts for $\sim 10 \%$ of all gastric cancers (GC). Epstein-Barr virus nuclear antigen 1 (EBNA1), which is critical for the replication and maintenance of the EBV latent genome, is consistently expressed in all EBVaGC tumors. We previously developed small molecule inhibitors of EBNA1. In this study, we investigated the efficacy and selectivity of an EBNA1 inhibitor in cell-based and animal xenograft models of EBV-positive and EBV-negative gastric carcinoma.

Methods We tested the potency of an EBNA1 inhibitor, VK-1727, in vitro and in xenograft studies, using EBV-positive (SNU719 and YCCEL1) and EBV-negative (AGS and MKN74) GC cell lines. After treatment, we analyzed cell viability, proliferation, and RNA expression of EBV genes by RT-qPCR.

Results Treatment with VK-1727 selectively inhibits cell cycle progression and proliferation in vitro. In animal studies, treatment with an EBNA1 inhibitor resulted in a significant dose-dependent decrease in tumor growth in EBVaGC xenograft models, but not in EBV-negative GC xenograft studies. Gene expression analysis revealed that short term treatment in cell culture tended towards viral gene activation, while long-term treatment in animal xenografts showed a significant decrease in viral gene expression.

Conclusions EBNA1 inhibitors are potent and selective inhibitors of cell growth in tissue culture and animal models of EBV-positive GC. Long-term treatment with EBNA1 inhibitors may lead to loss of EBV in mouse xenografts. These results suggest that pharmacological targeting of EBNA1 may be an effective strategy to treat patients with EBVaGC.
\end{abstract}

Keywords Epstein-Barr virus $\cdot$ Epstein-Barr nuclear antigen $1 \cdot$ Gastric cancer $\cdot$ Xenograft antitumor assays

\section{Introduction}

Gastric cancer (GC) is an aggressive and heterogenous disease and is a leading cause of cancer mortality in the world. In the United States, GC makes up $6.8 \%$ of total cancer cases and $8.8 \%$ of total cancer-associated deaths [1]. There are four types of GC diagnosed based on the

Troy E. Messick

troymessick@gmail.com

1 The Wistar Institute, 3601 Spruce Street, Philadelphia, PA 19104, USA

2 Division of Infectious Diseases, Brigham and Women's Hospital, Harvard Medical School, Boston, MA 02115, USA

3 Present Address: Tufts University, Boston, USA

4 Present Address: GlaxoSmithKline, Collegeville, USA appearance of cancerous cells in different cell types and layers of the stomach with adenocarcinomas accounting for $90 \%$ of GC; adenocarcinomas are further divided into cardia (the top part of the stomach) and noncardia (the lower part of the stomach) cancers. Several environmental risk factors, including the infectious agents Helicobacter pylori and Epstein-Barr virus (EBV) are highly associated with subtypes of GC. It is estimated that EBV-associated gastric carcinomas (EBVaGC) comprise approximately $10 \%$ (11\% of males and 6\% of females) of all gastric cancers and represent the most common malignancy caused by EBV infection [2]. The majority of EBVaGCs are lymphoepithelial-like carcinomas with a distinct molecular and clinical profile compared to EBV negative GCs. Moreover, EBVaGCs respond differently to anti-neoplastic therapy than to non-EBV GC and have different mean survival times, indicating EBVaGC is a distinct subtype 
that requires specific therapeutic strategies [3]. Many EBVaGCs acquire resistance to standard of care chemotherapeutic agents and there are currently no EBV specific therapeutics available for treating EBVaGC.

EBV is a ubiquitous human $\gamma$-herpesvirus virus that is associated with diverse lymphoid and epithelial malignancies [4]. EBV typically infects and establishes long-term latent infection in B lymphocytes, but also replicates in epithelial cells in the oropharynx. EBV epithelial malignancies include endemic forms of nasopharyngeal carcinoma (NPC) and more recently discovered in subtypes of gastric carcinomas. Viral DNA structural analysis indicates that EBV positive cells in NPC and EBVaGC are monoclonal indicating that EBV infection precedes the clonal expansion of the carcinoma [5, 6]. EBV maintains a stable latent infection in EBVaGC with viral gene expression limited to Epstein-Barr nuclear antigen 1 (EBNA1), BamHI fragment A rightward transcript (BART), and Epstein-Barr virus-encoded small RNAs (EBER). However, in about $40 \%$ of cases, latent membrane protein 2A (LMP2A) is also expressed [5]. With respect to histopathology, lymphoepithelioma (LE)-like GC has been characterized as an undifferentiated carcinoma with high lymphocytic infiltration. It is also worth noting that LEGC resembles NPC histologically and shares some common genetic and epigenetic alterations, including DNA hypermethylation $[7,8]$.

EBNA1 is the only virally encoded protein consistently expressed in all EBV-positive cancers [9, 10]. Experiments with siRNA knockdown of EBNA1 demonstrate that it is required for persistence of the EBV genome and continued proliferation of EBV-positive cells both in vitro and in vivo [11-13]. EBNA1 binds to the viral origin of replication (OriP) and recruits cellular replication machinery to promote viral genome replication and episomal maintenance [10, 14]. EBNA1 promotes immortalization and host cell survival by manipulating several cellular processes including p53 stabilization and pro-apoptotic pathways $[15,16]$. In addition to regulating the transcription of several viral latency genes, EBNA1 also binds directly to promoter regions and regulates the expression of several cellular genes, including the GCspecific tumor suppressor genes gastrokine 1 and 2 [17].

We previously reported the discovery of a series of small molecule inhibitors that block EBNA1-DNA binding [18, 19]. EBNA1 inhibitors show activity in several biochemical and cell-based assays, including chromatin immunoprecipitation (ChIP) and DNA replication assays. In addition, EBNA1 inhibitors suppress tumor growth in several EBVdependent xenograft models, including patient-derived xenografts for NPC. In this paper, we extend previous studies to investigate the efficacy and selectivity of EBNA1 inhibitors in tissue culture and mouse xenograft models of EBVpositive and negative GC. We observe significant tumor growth inhibition in EBV-positive GC xenografts, but not in EBV-negative xenografts. We also characterize viral gene expression after treatment.

\section{Materials and methods}

\section{Cell lines and reagents}

The identity of EBV-positive and negative cell lines [LCL352 (B cell/LCL, EBV ${ }^{+}$), BJAB (B cell, EBV ${ }^{-}$), C666-1 (NPC, EBV $\left.{ }^{+}\right), \mathrm{HK}-1\left(\mathrm{NPC}, \mathrm{EBV}^{-}\right)$, YCCEL1 $\left(\mathrm{GC}, \mathrm{EBV}^{+}\right)$, SNU719 $\left(\mathrm{GC}, \mathrm{EBV}^{+}\right)$, AGS $\left(\mathrm{GS}, \mathrm{EBV}^{-}\right)$, and MKN74 $\left.\mathrm{EBV}^{-}\right)$] were confirmed by short tandem repeat microsatellite testing. Cell lines were grown in RPMI-1640 medium (Gibco, BRL) containing 10\% fetal bovine serum (FBS; Gibco, Gaithersburg, MD, USA) penicillin and streptomycin $(50 \mathrm{U} / \mathrm{ml})$, and L-glutamine. All cells were incubated at $37{ }^{\circ} \mathrm{C}$ under a $5 \% \mathrm{CO}_{2}$ humidified atmosphere. For bioimaging studies, the cell lines were transduced with a lentivirus constitutively expressing green fluorescent protein (GFP)-Internal Ribosome Entry Site (IRES)-luciferase transgene.

\section{Resazurin cell respiration assay}

Cells were plated at $8 \times 10^{3}$ cells (in $100 \mu \mathrm{l}$ ) per well in a 96-well plate. Inhibitors were added $24 \mathrm{~h}$ later over a 10 -point concentration range with two-fold dilutions ( 0.1953 to $100 \mu \mathrm{M}$ ) in quadruplicate wells. As positive and negative controls, DMSO alone $(0.4 \%)$ and puromycin $(20 \mu \mathrm{g} / \mathrm{ml})$ treated wells, respectively, were also plated in quadruplicate wells. After $72 \mathrm{~h}$, resazurin $(20 \mu \mathrm{l}$, final $50 \mu \mathrm{M})$ was added to each well. After $6 \mathrm{~h}$, plates were read on a PerkinElmer EnVision XCite multilabel plate reader (excitation, $560 \mathrm{~nm}$; emission, $590 \mathrm{~nm}$ ).

\section{BrdU proliferation assay}

Cells were plated at $5 \times 10^{4}$ per well (in $200 \mu \mathrm{l}$ ) in a 96-well plate and treated with DMSO alone $(0.4 \%)$ or VK-1727 $(0.25$ or $2.5 \mu \mathrm{M})$. At 24 and $48 \mathrm{~h}$ after treatment, the plates were centrifuged at $1000 \mathrm{rpm}$ for $5 \mathrm{~min}$, and the medium was carefully aspirated and replaced with fresh medium containing DMSO alone or EBNA1 inhibitor at the appropriate concentration. After $72 \mathrm{~h}$, a BrdU cell proliferation assay was performed according to the manufacturer's instructions (CytoSelect BrdU Cell Proliferation ELISA Kit, Cell Biolabs, Inc.). Briefly, $10 \mu 1$ of a $10 \times$ BrdU solution $(100 \mu \mathrm{M} \mathrm{BrdU})$ was added to each well, and plates were incubated at $37^{\circ} \mathrm{C}$. Three hours later, cells were centrifuged at $1000 \mathrm{rpm}$ for $5 \mathrm{~min}$, washed three times with $100 \mathrm{ul}$ of phosphate-buffered saline (PBS), and treated with fix/denature solution. Thereafter, cells were incubated with $100 \mu$ of 
anti-BrdU antibody for $1 \mathrm{~h}$. Cells were washed three times with $1 \times$ wash buffer, and after incubation with a secondary HRP-conjugated antibody, a substrate solution was applied. Plates were read on a PerkinElmer EnVision XCite multilabel plate reader (absorbance, $450 \mathrm{~nm}$ ). Data are represented as a percentage decrease in BrdU compared to DMSO treated control.

\section{Analysis of cell cycle kinetics}

LCL352 (B cell/LCL, EBV ${ }^{+}$), BJAB (B-cell, EBV ${ }^{-}$), C666-1 $\left(\mathrm{NPC}, \mathrm{EBV}^{+}\right), \mathrm{HK}-1\left(\mathrm{NPC}, \mathrm{EBV}^{-}\right), \mathrm{YCCEL} 1\left(\mathrm{GC}, \mathrm{EBV}^{+}\right)$, SNU719 $\left(\mathrm{GC}, \mathrm{EBV}^{+}\right)$, AGS $\left(\mathrm{GS}, \mathrm{EBV}^{-}\right)$, and MKN74 $\left.\mathrm{EBV}^{-}\right)$, cells were seeded at $2.4 \times 10^{5}$ cells/well in 6-well plates and exposed to VK-1727 $(10 \mu \mathrm{M}$ and $25 \mu \mathrm{M})$ in biological triplicates per each condition. After $72 \mathrm{~h}$, cells were permeabilized with cold, $70 \%$ ethanol and resuspended in PBS containing PI $(10 \mathrm{mg} / \mathrm{mL})$ and RNAse A solution $(100 \mu \mathrm{g} / \mathrm{mL})$. Flow cytometry was performed on a BD-LSR II (BD Biosciences; Bedford, MA) and data were analyzed using FloJo software (Ashland, OR).

\section{Cell growth assay}

Each cell line was seeded at $2.4 \times 10^{5}$ cells/well overnight in a 6-well plate and treated the next day with EBNA1 inhibitor (VK-1727) alone or in combination with ganciclovir (GCV). $72 \mathrm{~h}$ later, cells were stained with trypan blue and cell counts were obtained using the Countess II cell counter.

\section{Animals}

All institutional and national guidelines for the care and use of laboratory animals were followed. All procedures were approved by The Wistar Institute Institutional Animal Care and Use Committee (IACUC) in accordance with the Animal Welfare Act (AWA) and PHS Policy on Humane Care and Use of Laboratory Animals. All mice in this study were managed in accordance with the NIH Office of Laboratory Animal Welfare: "PHS Policy on the Humane Care and Use of Research Animals"; the recommendations of the American Association for Accreditation of Laboratory Animal Care (AAALAC).

Xenograft studies were performed in NSG mice (NOD. Cg-Prkdc ${ }^{\text {scid }}$ Il2 rgtm1Wjl/ScJ) bred in-house at The Wistar Institute under protocol number 112092 . There is a preponderance of GC in males (2:1; male vs female) and in the developing world, especially in Eastern Asia [1]. Therefore, both male and female mice were used in this study. All mice were enrolled in their respective studies at 8 weeks of age and housed in micro-isolator cages in a designated, specific pathogen-free facility at The Wistar Institute (Philadelphia, PA), where they were fed sterile food and water ad libitum.
Mice were euthanized via $\mathrm{CO}_{2}$ administration according to the American Association for Accreditation of Laboratory Animal Care (AAALAC) euthanasia guidelines.

\section{Tumor implantation, grouping, and equalization}

Mice were anesthetized using isoflurane and engrafted with a cell suspension ( $>98 \%$ viability) of $5 \times 10^{6}$ cells resuspended in $1 \times$ PBS (pH 7.4) and mixed with $20 \%$ of cold Matrigel (Corning Life Sciences) and maintained on ice. Cells were injected subcutaneously into the flank of each animal. Animals were weighed three-times per week and monitored daily. All tumors were measured by caliper, and tumor volume was calculated as follows: tumor volume $=$ [length $(\mathrm{L}) \times$ width $\left.(\mathrm{W})^{2}\right] / 2$. After the average tumor volume reached $100 \mathrm{~mm}^{3}$, mice were grouped $(n=8$ per group; 4 male and 4 female); between 28 and 45 days post engraftment depending on the cell line. Groups were normalized by bioluminescent imaging using the spectrum IVIS CT bioluminescent imaging system (Perkin-Elmer; Waltham, MA) to ensure the average flux (photons/sec) was equivalent across groups and to monitor cell growth throughout the study.

After randomization, treatment (vehicle or $10 \mathrm{mg} / \mathrm{kg}$ VK-1727) was administered by intraperitoneal injection twice a day (bis in die, b.i.d.) in a dose volume of $10 \mathrm{ml} / \mathrm{kg}$ body weight. Tumors growth was measured by IVIS bioluminescent imaging.

\section{Visualization and quantitation of tumor growth using the xenogen IVIS bioluminescent imaging system}

For imaging studies, mice were injected with D-luciferin (Gold Biotechnology), i.p. at a dose of $7.5 \mathrm{mg} / \mathrm{kg}$ in a dose volume of $10 \mathrm{ml} / \mathrm{kg}$ body weight $15 \mathrm{~min}$ prior to imaging; this was the optimal interval between luciferin injection and bioluminescent imaging as determined by an initial kinetic curve for these cell lines in mice. Mice were anesthetized using isoflurane prior to and during imaging.

\section{Ki67 analysis by flow cytometry}

Tumor sections were homogenized and filtered through a $45 \mu \mathrm{M}$ filter, followed by filtration through a $35 \mu \mathrm{M}$ filter. Cells were washed twice with PBS and then fixed with $70 \%$ cold ethanol for one hour at $-20{ }^{\circ} \mathrm{C}$. Cells were then washed three times with cell staining buffer (PBS with 5\% fetal bovine serum and $0.09 \%$ sodium azide). After decanting cell staining buffer $100 \mu \mathrm{l}$ of cell suspension was mixed with an antibody to Ki67 conjugated with Alexa 594 (Biolegend, San Diego, CA) and incubated at room temperature for $30 \mathrm{~min}$. Cells were washed three times with cell staining buffer and flow cytometry was performed on a BD-LSR II 
(BD Biosciences; Bedford, MA). Data were analyzed using FloJo software (Ashland, OR).

\section{Compound formulation and treatment schedules}

For cell-based assays, compounds were weighed and resuspended in DMSO at a concentration of $50 \mathrm{mM}$, prior to dilution to desired concentration while maintaining a final concentration of DMSO at $0.4 \%$. For animal studies, compounds were weighed and transferred to graduated tubes, and formulation reagents were added slowly dropwise in the following order: 1.0\% Tween 80 (Sigma), 5\% dimethylacetamide (Sigma), 15\% PEG400 (polyethylene glycol, molecular weight 400) (Sigma), 10\% propylene glycol, 30\% PBS, and $39 \%$ water; $0.01 \%$ of $1 \mathrm{~N} \mathrm{NaOH}$ was added to clarify the final solution. The vehicle control contained formulation reagents without the compounds.

\section{Gene expression analysis}

Tumor sections were flash-frozen, and later, RNA was isolated using the RNeasy Mini Kit (Qiagen) and treated with deoxyribonuclease (Qiagen). Reverse transcription followed by real-time (or quantitative) PCR (RT-qPCR) was used to measure gene expression levels of EBV genes. Primers used for qPCR of EBV genes include: EBNA1 F (5'-GGTCGT GGACGTGGAGAAAA-3'), EBNA1 R (5'-GGTGGAGAC CCGGATGAT G-3'); EBER2 F (5'-TTGCCCTAGTGGTTT CGGACACA-3'), EBER1 F (5'-TTTGCTAGGGAGGAG ACGTGTGT-3'), EBER1 R (5'-AAGCAGAGTCTGGGA AGACAACCA-3'); EBER2 R (5'-ACTTGCAAATGCTCT AGGCGGGAA-3'); ZTA F (5'-TCTGAACTAGAAATA AAGCGATACAAGAA-3'), ZTA R (5'-TTGGGCACA TCTGCTTCAAC-3'); LMP1 F (5'-TCCAGAATTGAC GGAAGAGGTT-3'), LMP1 R (5'-GCCACCGTCTGTCAT CGAA-3'); BARF0 F(5'-GGTACGCTGTAGAAGCTGTTG AAG-3'), BARF0 R (5'-TGATATGGCCAGGCATCGA-3'); BART miRNA exon $1 \mathrm{~F}$ (5'-GTAGGCACTAGCCTCTTC ATGTGA-3'), BART miRNA exon 2 R (5'-GGTAAGGGC TACGTCCGAGTCT-3'); BART miRNA exon 5 F (5'-GCT TGATGACGATGCCACAT- $3^{\prime}$ ), and BART miRNA exon 5 R (5'-AATGCGCCGTCATTCCAT-3'). GUSB was used as a cellular control: GUSB F (5'-CGCCCTGCCTATCTG TATTC-3') and GUSB R (5'-TCCCCACAGGGAGTGTGT AG-3').

The average cycle threshold (CT) was determined by three independent samples. Template-negative (quantitative PCR reaction mixtures without cDNA) and RT-negative (RNA after genomic DNA elimination) conditions were used as controls. All data were normalized to the housekeeping gene GUSB and quantitative PCR data for the relative quantification were calculated with the $\Delta \Delta \mathrm{Ct}$ method. The level of EBNA1 transcript in cells treated with vehicle control (DMSO; $0.4 \%$, vol/vol) was set as 1 .

\section{EBV viral load}

Tumor sections were flash-frozen, and later, homogenized by tissuelyser and DNA was isolated DNeasy Blood and Tissue kit (Qiagen, Hilden, Germany). PCR was used to quantify EBV viral load using a standard curve generated with Namalwa cells (two copies per cell). Primers used include: EBNA1 F (5'- TCA TCA TCA TCC GGG TCT CC-3'); EBNA1 R (5'- CCT ACA GGG TGG AAA AAT GGC $\left.-3^{\prime}\right)$; $\beta$-actin $F\left(5^{\prime}\right.$ - GCC ATG GTT GTG CCA TTA CA-3'); $\beta$-actin R (5'- GGC CAG GTT CTC TTT TTA TTT CTG-3').

\section{Dot blot for DNA methylation}

YCCEL1 and SNU719 were plated on $150 \mathrm{~mm}$ plates at a seeding density of $3 \times 10^{6}$ cells per plate. Twenty-four hours later, EBNA1 inhibitor (VK-1727) was added at a concentration of 0,10 , or $20 \mu \mathrm{M}$ to duplicate plates. The DNAdemethylating agent decitabine (5-Aza-2'deoxycytadine; Sigma, St. Louis, MO) was used at $7.5 \mu \mathrm{M}$ as a positive control. All plates had a final DMSO concentration of $0.4 \%$. Medium was refreshed with EBNA1 inhibitor, DMSO alone, or decitabine 3 days later. At day 7, cells were harvested, and genomic DNA was extracted from the cells using the DNeasy Blood and Tissue kit (Qiagen, Hilden, Germany). One $\mu \mathrm{g}$ of genomic DNA was denatured in $0.1 \mathrm{M} \mathrm{NaOH}$ for 10 min at $95{ }^{\circ} \mathrm{C}$, neutralized with $1 \mathrm{M}$ ammonium acetate and diluted by two-fold. Four $\mu 1$ of serial diluted genomic DNA was spotted onto a Hybond-N + membrane (PerkinElmer, MA, USA). Air-dried membranes were subjected to DNA crosslinking, using a UV crosslinker (Spectronics Corporation, NY, USA). After blocking in 5\% BSA in TBST for $1 \mathrm{~h}$, membranes were incubated with 1:1000 diluted anti5-methylcytosine (5-mC) monoclonal antibody (Abcam, Cambridge, UK, ab10805) at $4{ }^{\circ} \mathrm{C}$ overnight, washed and then probed with secondary antibody for $1 \mathrm{~h}$ at room temperature. After washing, dot blots were developed by incubation with ECL chemiluminescence for $1 \mathrm{~min}$. Images were captured and analyzed by Li-Cor Fc platform.

\section{Results}

\section{EBNA1 inhibitor decrease the proliferation of EBV-positive, but not EBV-negative, GC cells}

To determine the effect of the EBNA1 inhibitor VK-1727 (Fig. 1a) treatment on GC cell line proliferation, SNU719 $\left(\mathrm{GC}, \mathrm{EBV}^{+}\right)$YCCEL1 cells $\left(\mathrm{GC}, \mathrm{EBV}^{+}\right) \mathrm{AGS}\left(\mathrm{GC}, \mathrm{EBV}^{-}\right)$ 


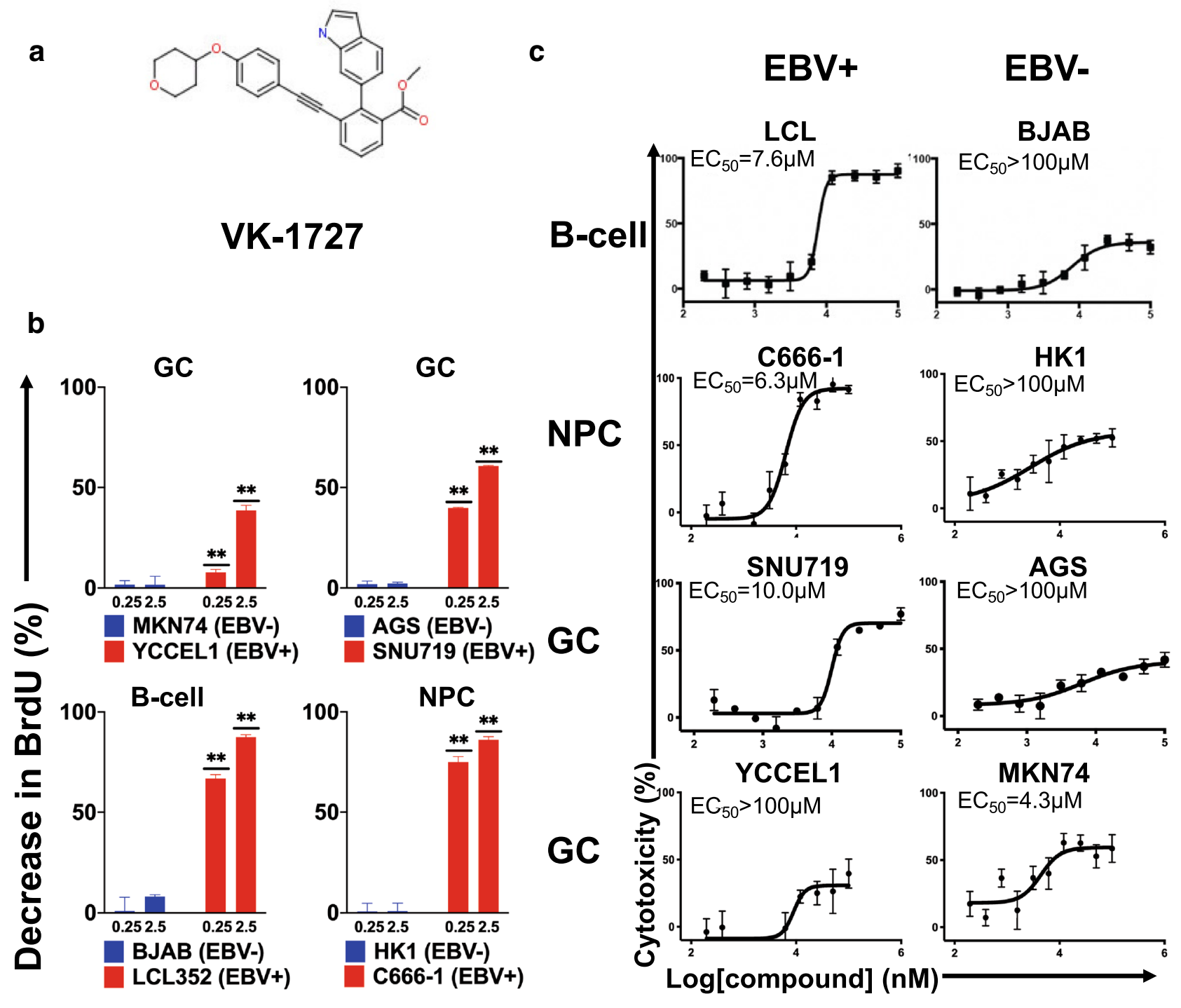

Fig. 1 Selective inhibition of EBV-positive cell lines by EBNA1 inhibitor VK-1727. a Structure of EBNA1 inhibitor VK-1727. b Selective inhibition of cell proliferation as measured by significant decreases (student $t$ test; ${ }^{* *} p<0.0001$ ) in BrdU compared to DMSO control in EBV-positive (red), but not EBV-negative (blue) cell lines at 0.25 and $2.5 \mu \mathrm{M}$. c Resazurin-based cell metabolism assay using

MKN74 (GC, $\left.\mathrm{EBV}^{-}\right)$were treated with vehicle control (0.4\% DMSO) or EBNA1 inhibitor VK-1727 with a dose of $0.25 \mu \mathrm{M}$ or $2.5 \mu \mathrm{M}$. We performed a cell proliferation assay to measure 5-bromo-2'-deoxyuridine (BrdU) incorporation at 3 concentrations, $0,0.25$ and $2.5 \mu \mathrm{M}$. We found that EBNA1 inhibitor selectively inhibits proliferation of EBVpositive SNU719 and YCCEL1 cells, but not similarly growing EBV-negative AGS and MKN74 cells (Fig. 1b). These results are similar to results obtained using other EBV positive and negative cell lines, including LCL352 (LCL/B-cell, $\left.\mathrm{EBV}^{+}\right), \mathrm{BJAB}\left(\mathrm{B}\right.$-cell, $\left.\mathrm{EBV}^{-}\right), \mathrm{C} 666-1\left(\mathrm{NPC}, \mathrm{EBV}^{+}\right)$, and HK1 (NPC, $\mathrm{EBV}^{-}$). These results suggest that VK-1727 is
EBV-positive lymphoid cells LCL $\left(\mathrm{EBV}^{+}\right)$vs BJAB $\left(\mathrm{EBV}^{-}\right)$(top panels); NPC cells C666-1 (EBV $\left.{ }^{+}\right)$vs $\mathrm{HK}-1\left(\mathrm{EBV}^{-}\right)$(middle panels); and gastric carcinoma cells SNU719 $\left(\mathrm{EBV}^{+}\right)$vs AGS $\left(\mathrm{EBV}^{-}\right)$(bottom panels) in a resazurin based cell viability assay, $72 \mathrm{~h}$ after treatment

a potent and selective inhibitor of cell proliferation of EBVpositive GC cells compared with EBV-negative GC cells. In addition, the inhibition of proliferation in EBV-positive B-cells and NPC cells confirms that VK-1727 inhibits growth of EBV positive cells, regardless of their cell lineage or latency type.

As an additional measure of the effect of the EBNA1 inhibitor on cell viability, we used a resazurin assay to measure changes in metabolic activity of cells treated with VK-1727 (Fig. 1c and S1). To determine the selectivity of EBNA1 inhibitor, the EBV-positive and negative cell lines were treated with VK-1727 and $\mathrm{EC}_{50}$ values calculated 
(Fig. 1b). VK-1727 decreased the proliferation of most EBV-positive cells in a dose -dependent manner (Fig. 1b). The $\mathrm{EC}_{50}$ value for the EBV-positive cell lines LCL352, C666-1, and SNU719 cells were $7.9 \mu \mathrm{M}, 6.3 \mu \mathrm{M}$, and $10 \mu \mathrm{M}$, respectively), compared to the EBV-negative cell lines BJAB, HK1, and AGS, which were all had $\mathrm{EC}_{50} \mathrm{~S}$ greater than $100 \mu \mathrm{M}$. Similar results were observed after $96 \mathrm{~h}$ of incubation (Fig S1). Cell viability as measured by resazurin did not reach the $50 \%$ level at even the highest concentration of compound for the EBV-negative cell lines BJAB (B cell), HK1 (NPC), and AGS (GC). The selective inhibition was consistent for all cells except for YCCEL1 $\left(\mathrm{GC}, \mathrm{EBV}^{+}\right)$and MKN74 $\left(\mathrm{GC}, \mathrm{EBV}^{-}\right)$, where the EC50 for YCCEL1 was greater than $100 \mu \mathrm{M}$, in spite of the antiproliferative effect of VK-1727 measured by other assays (Fig. 1b and Fig. 3b) and the decrease in cell number and cellular adherence observed in YCCEL1 treated with
$10 \mu \mathrm{M}$ or $25 \mu \mathrm{M}$ VK-1727 by microscopy (Fig. 2a and Figure S2).

\section{EBNA1 inhibitor treatment perturbs the cell cycle in EBV-positive GC and other EBV-positive cells}

To begin to understand the mechanism of action of VK-1727 in inhibiting cell proliferation, we first analyzed the cell cycle profiles for the EBV-positive GC line SNU719 and the EBV-negative GC line AGS using either $10 \mu \mathrm{M}$ or $25 \mu \mathrm{M}$ VK-1727 or DMSO as control for $72 \mathrm{~h}$ (Fig. 2b). Although cell cycle populations for AGS remained consistent during treatment with VK-1727, the cell cycle profile of EBV-positive SNU719 was clearly perturbed by VK-1727 treatment and a flattening of the $\mathrm{G} 2$ peak and increase in the $\mathrm{G} 1$ population was observed (Fig. $2 \mathrm{~b}$ ). We followed this initial experiment to include two EBV-positive GC lines a

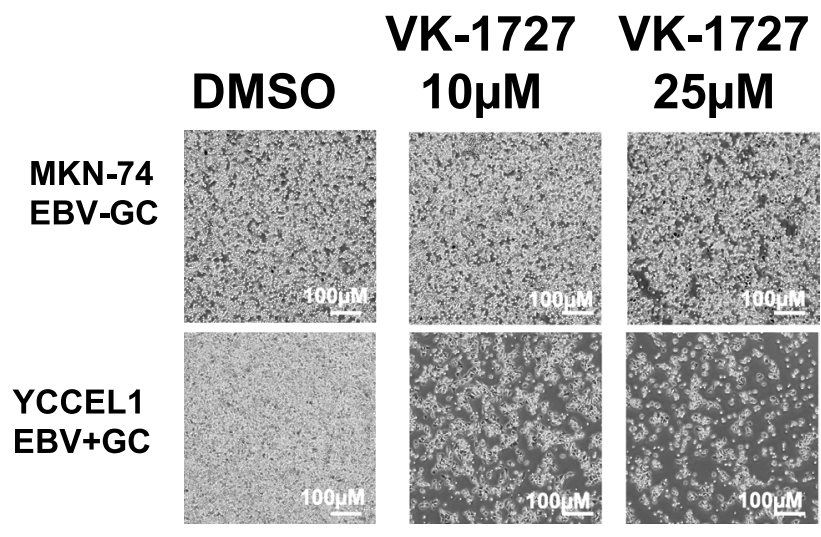

b



C

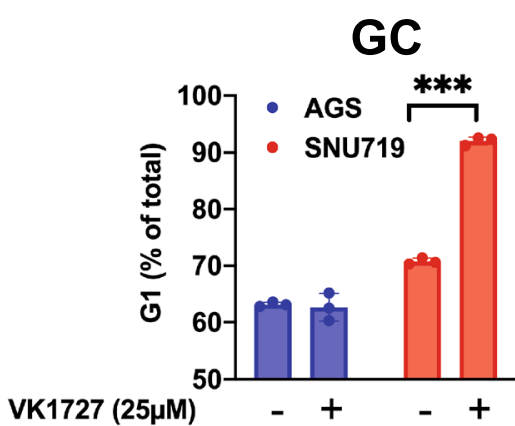

Fig. 2 EBNA1 inhibitor VK-1727 inhibits cell cycle progression. a Images of MKN74 $\left(\mathrm{EBV}^{-}\right)$and YCCEL1 $\left(\mathrm{EBV}^{+}\right)$GC cells with $4 \times$ objective using the Nikon TIE inverted microscope $72 \mathrm{~h}$ after treatment with DMSO or VK-1727 $(10 \mu \mathrm{M}$ or $25 \mu \mathrm{M})$. Bar $=100 \mu \mathrm{m})$ b Cell cycle profiles of AGS $\left(\mathrm{EBV}^{-}\right)$and YCCEL1 $\left(\mathrm{EBV}^{+}\right)$cells treated with DMSO and 10 or $25 \mu \mathrm{M}$ VK-1727 measured by flow cytometry analysis of propidium iodide staining. Cell cycle changes, including a decrease in G2 (box) and an increase in G1, are observed in SNU719 $\left(\mathrm{EBV}^{+}\right)$, but not $\mathrm{AGS}\left(\mathrm{EBV}^{-}\right)$gastric carcinoma cells. c Cell cycle analysis of EBV-positive and EBV-negative GC, B cells, and NPC cells treated with DMSO or VK-1727. G1 populations are represented as a percentage as total (student $t$ test; $* * p<0.001$, $* * * p<0.0001)$. An increase in $\mathrm{G} 1$ as a percentage of the total population is increased in EBV-positive cells of B cell, GC, and NPC origin (LCL, SNU719, YCCEL1, and C666-1), not in EBV-negative cells (student $t$ test; $* * p<0.001$ ) 
a

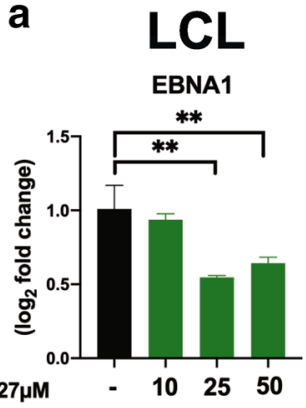

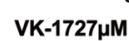

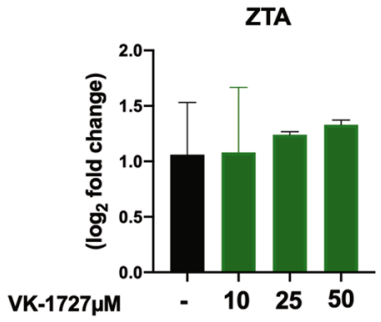

C666-1

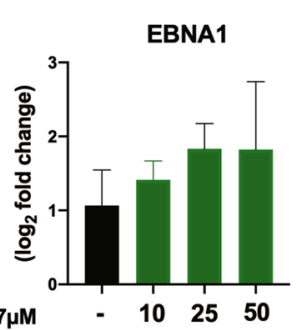

SNU719

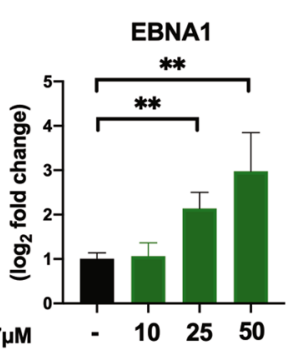

YCCEL1

EBNA1

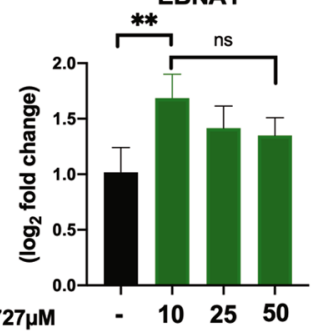

b
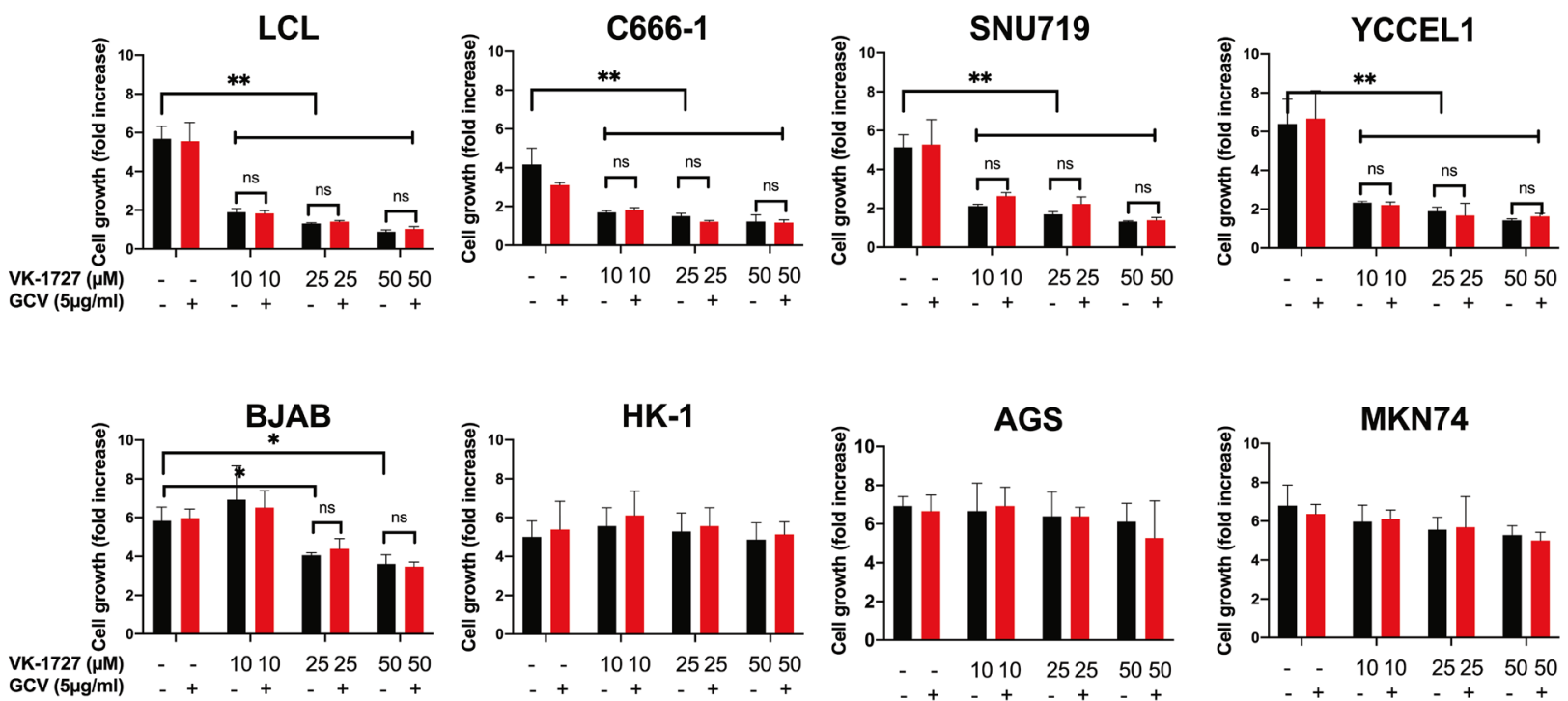

Fig. 3 EBV gene expression patterns in vitro and inhibition of proliferation in EBV-positive cell lines. a Expression of EBV genes EBNA1 and ZTA in EBV-positive cell lines measured by $\Delta \Delta \mathrm{CT}$ method (student $t$ test; **p<0.001, ***p<0.0001). b Cell counts are plotted as fold increase in cell number after $72 \mathrm{~h}$ treatment. Each bar represents mean fold increase \pm SD of 3 replicates (EBV-positive lines: SNU719, C666-1, YCCEL1, and LCL352; EBV-negative lines: AGS, HK-1, MKN74, and BJAB). Cells were treated with DMSO, VK-127 (at 10,25 , or $50 \mu \mathrm{M})$, and VK-1727 with GCV $(5 \mu \mathrm{g} / \mathrm{ml})$

effects on the cell cycle profiles of the EBV-negative cell lines (AGS, MKN74, BJAB, or HK1) (Fig. 2b). These data suggest that the VK1727 inhibits cell cycle progression in EBV-positive cell types, again, regardless of their cell lineage or latency state. Notably, we did not see an increase in the $<$ G1 population, suggesting that the EBNA1 inhibitor VK-1727 is cytostatic, rather than cytotoxic under these conditions. 


\section{EBNA1 inhibitors increase EBNA1 transcription and block cell proliferation of EBVaGC cell lines in vitro}

EBV gene expression was measured after addition of VK-1727 to EBV positive B cells (LCL352), NPC cells (C666-1), and EBVaGC cells (SNU719 and YCCEL1) (Fig. 3). For these studies, we focused on the EBV latency gene EBNA1 and the EBV lytic gene BZLF/ZTA. In LCLs, EBNA1 gene expression was significantly reduced $72 \mathrm{~h}$ after treatment with $25 \mu \mathrm{M}$ and $50 \mu \mathrm{M}$ of VK-1727; ZTA expression was unaffected (Fig. 3a). In contrast, treatment with VK-1727 increased EBNA1 expression in both EBVaGC cell lines SNU719 and YCCEL1. These data suggest that VK-1727 is inhibiting EBNA1 in both LCLs and EBVaGC cells and indicates that the short-term effects of this treatment are different in cells of different lineages (B cell compared with GC) and latency types (latency III vs latency I, respectively).

It was, therefore, of interest to determine whether EBNA1 inhibitor treatment induced lytic activation in EBV-positive cells, we treated EBV-positive cell lines (LCL, C666-1, SNU719 and YCCEL1) with 10-30 $\mu \mathrm{M}$ VK-1727 alone or in the presence of the antiviral drug ganciclovir (GCV), a synthetic analogue of 2'-deoxy-guanosine that is activated and phosphorylated in cells expressing lytic cycle enzymes of EBV. GCV would be expected to further inhibit viability of cells expressing EBV lytic enzymes. When we measure cell proliferation, here measured as fold increase in cell numbers $72 \mathrm{~h}$ after treatment, we saw significant inhibition of cell proliferation in all EBV-positive cell lines (LCL352, C666-1, SNU719, and YCCEL1) treated with VK-1727, but not in EBV-negative cell lines (BJAB, HK1, AGS, and MKN74), with the exception of a decrease in $\mathrm{BJAB}$ proliferation at the highest concentrations of VK-1727 (Fig. 3b). However, there was no additive effect of GCV observed, suggesting that VK-1727 does not induce lytic activation of EBVaGC or other EBV-positive cell lines.

\section{EBNA1 inhibitors block EBV-driven tumor growth in vivo}

To assess the efficacy of EBNA1 inhibitors in vivo, we engrafted the EBV-positive GC cell lines SNU714 and YCCEL1 into NSG mice and assessed tumor growth by bioluminescence (Fig. 4a). After tumors were $>100 \mathrm{~mm}^{3}$, mice were assigned to treatment groups to equalize tumor sizes by both size and bioluminescence as measured by Flux (photons/sec). Eight mice per group (four male and four female) were assigned to be treated with vehicle, or $10 \mathrm{mg} / \mathrm{kg}$ VK-1727. Mice were administered compound or vehicle twice a day (b.i.d.) intraperitoneally for 24 days. We observed a significant decrease in tumor growth in
EBV-positive tumors (YCCEL1 and SNU719) when treated with VK-1727. In the SNU719 and YCCEL1 xenograft studies, we observe that treatment results in tumor growth inhibition (TGI) of $61.2 \%$ and $67 \%$, respectively, at $10 \mathrm{mg} / \mathrm{kg}$ VK-1727 compared to vehicle control. To assess the selectivity of EBNA1 inhibitors, we performed similar xenograft experiments using the AGS and MKN74 cell lines (Fig. 4b). A side-by-side comparison of bioluminescence showed that no growth inhibition was observed in EBV-negative GC tumors (AGS and MKN74) treated with VK-1727 (Fig. 4c). Treatment with VK-1727 did not result in any appreciable weight loss compared to vehicle control (Fig. 4d).

\section{Treatment with EBNA1 inhibitors significantly reduces latent viral gene expression and EBV-viral load in EBV-positive GC xenografts}

To assess the effect of treatment with EBNA1 inhibitors on viral gene expression, we isolated RNA from tumors at the end of the xenograft studies and performed quantitative RT-qPCR experiments for SNU719 (Fig. 5a) and YCCEL1 (Fig. 5b). We observe a significant $(p<0.001)$ reduction in EBNA1, EBER1 and EBER2 in SNU719 and YCCEL1 tumors extracted from VK-1727 treated animals compared to vehicle. LMP1 mRNA expression was reduced in YCCEL1, but not SNU719, while BART miRNA exon 5 (BART Ex5) was decreased in VK-1727 treated SNU719 tumors, but to a lesser extent in YCCEL1 (Figs. 5a, b). We also observed that EBV viral loads were reduced after 24 days of treatment (Fig. 5c). Others have shown that SNU719 cells do not express EBNA2 or LMP1 protein [20] and YCCEL1 cells have been characterized as expressing a modified latency program I [21]. GC cell lines AGS and MKN74 were confirmed to be EBV negative by qPCR (Figure S3).

\section{Treatment with EBNA1 inhibitors significantly reduces proliferation in EBV-positive GC xenografts}

To determine the effect of the EBNA1 inhibitor VK-1727 on proliferation in vivo, we measured Ki67 expression in tumors extracted from mice treated with VK-1727 (10 mg/ $\mathrm{kg}$ ) and vehicle by flow cytometry (Fig. 5d). Ki67 was significantly reduced in EBV-positive GC tumors (SNU719 and YCCEL1), but not AGS or MKN74, consistent with the observation that VK-1727 decreases the proliferation of these cells.

Treatment with EBNA1 inhibitors demethylates DNA in EBVaGC cell lines. To determine the effect of EBNA1 inhibition on the DNA hypermethylation profile of EBVaGC cell lines, we quantified by dot blot assay the global DNA methylation of EBVaGC cells treated with EBNA1 inhibitor or decitabine as a positive control (Fig. 6). We observed a modest, but significant DNA decrease in global DNA 
a

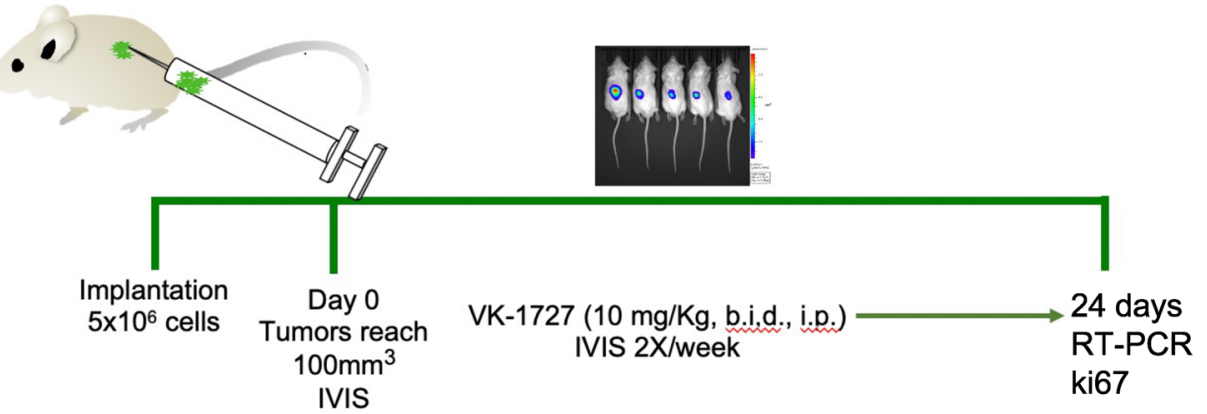

b $\quad \rightarrow$ Vehicle

$\rightarrow$ VK-1727 (10 mg/Kg. IP, BID)

C

AGS MKN74

AGS (EBV-)

MKN74 (EBV-)
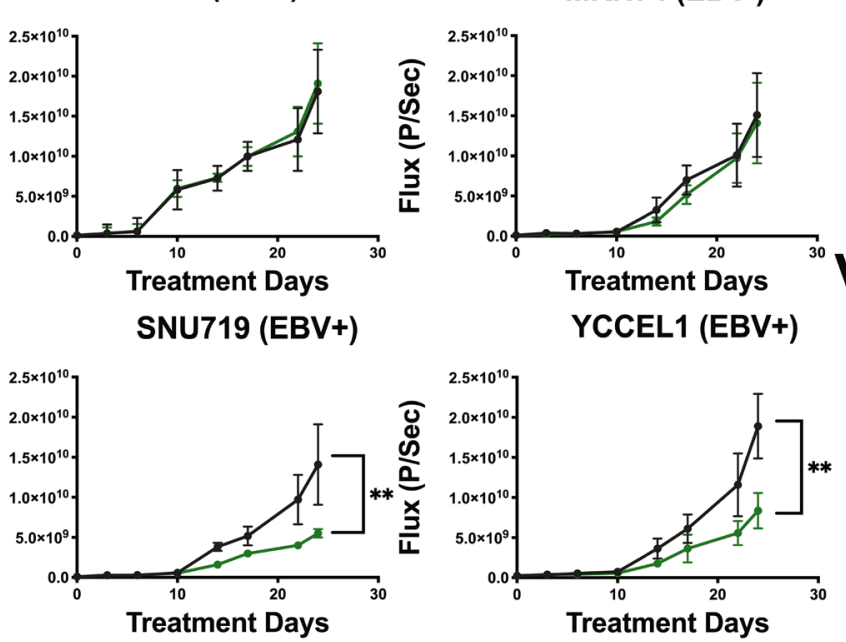
EBV-GC EBV-GC
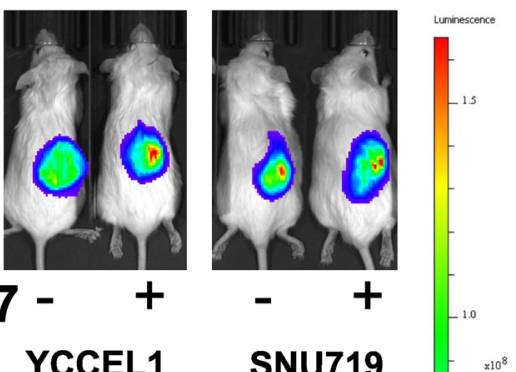

$\begin{aligned} \text { d } & \text { - Vehicle } \\ & \text { - VK-1727 (10 mg/Kg. IP, BID) }\end{aligned}$

VK-1727

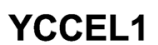
$E B V+G C$

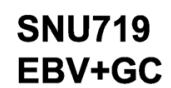

AGS (EBV-)

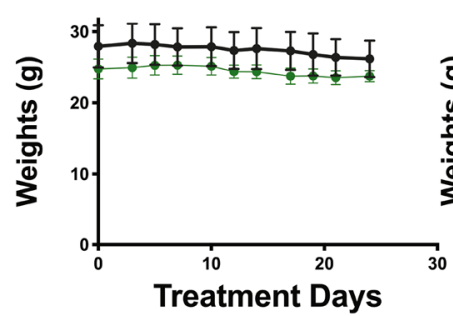

MKN74 (EBV-)

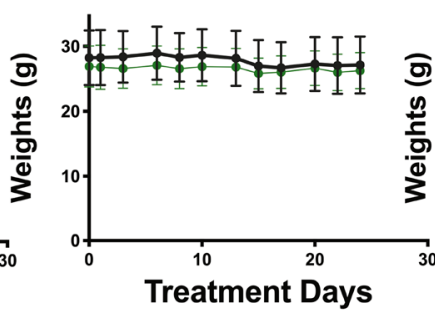

SNU719 (EBV+)

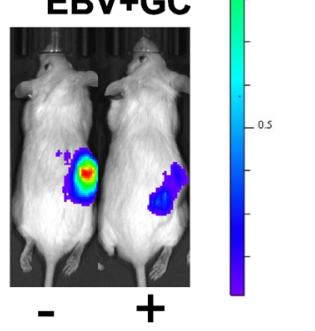

Fig. 4 VK-1727 inhibits EBV-positive GC tumor growth in xenografts. a Schema illustrating key features of the in vivo experiments that were performed with VK-1727. NSG mice were implanted with $5 \times 10^{6}$ SNU719, YCCEL1, AGS, or MKN cells subcutaneously. When tumors reached $100 \mathrm{~mm}^{3}$, mice were randomized and treated daily with 0 (vehicle) or $10 \mathrm{mg} / \mathrm{kg}$ VK-1727, twice daily (b.i.d.). During treatment, the mice were continuously imaged using a Spectrum IVIS CT bioluminescent imaging system. At day 24 , the mice were sacrificed, weighed, and tumors were collected for further analyses.
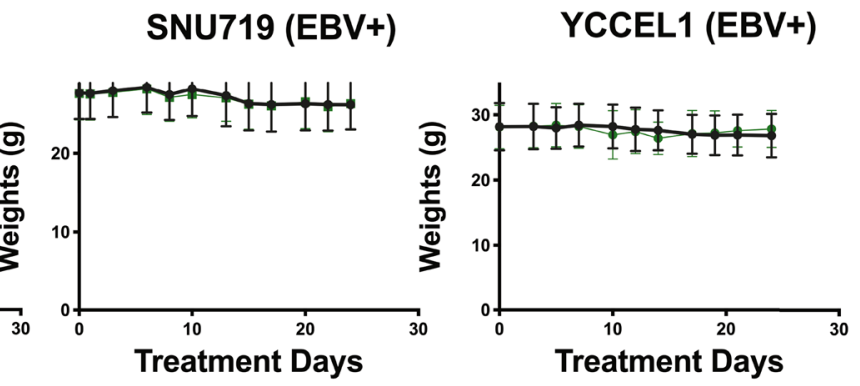

b Graphs showing the changes in bioluminescence flux (photons/s) over time (student $t$ test; $* * p<0.01$ ). c Images comparing the bioluminescence signals that were observed in mice implanted with GC cell lines treated with vehicle or VK-1727. For each pair, the left mouse was treated with vehicle and the right mouse was treated with VK-1727. d Graphs comparing the changes in weight that were observed in mice engrafted with GC cell lines and treated with vehicle or VK-1727, twice daily i.p. Treatment with VK-1727 was not associated with weight loss or other clinical signs 
a

SNU719

EBNA1
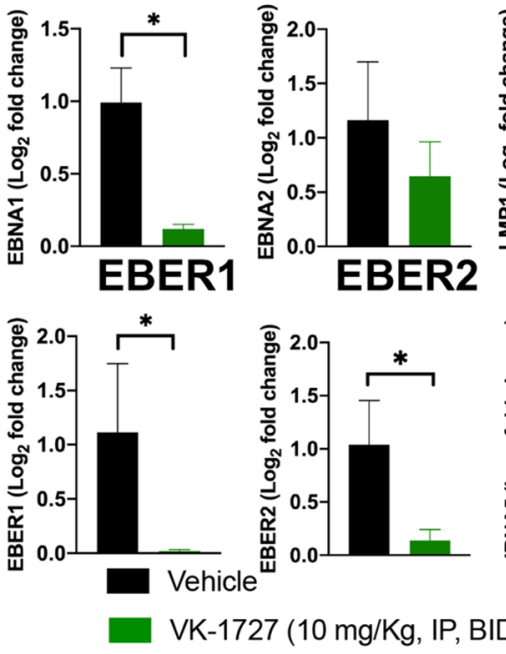

C

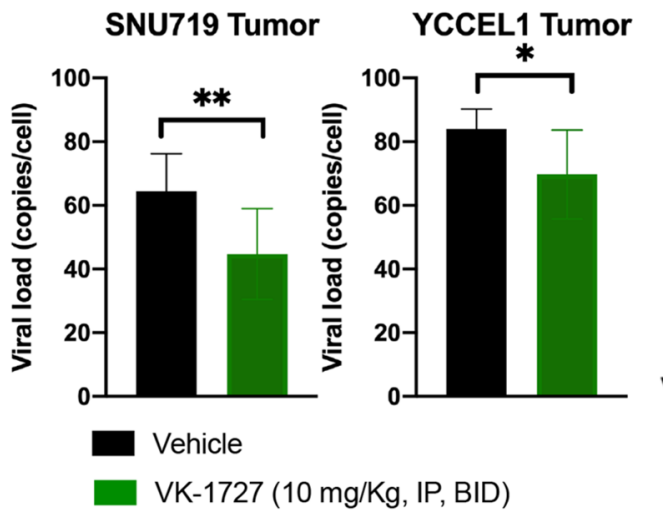

Fig. 5 EBV gene expression and cell proliferation is decreased in EBV-positive GC treated in vivo. a RT-PCR showing expression of EBNA1, EBNA2, LMP1, EBER1, EBER2, and BART miRNA exon 5 (BART Ex5) in SNU719 xenografts. b RT-PCR showing expression of EBNA1, EBNA2, LMP1, EBER1, EBER2, and BART

methylation after 7 days of treatment with the EBNA1 inhibitors in both SNU719 (Fig. 6a, b) and YCCEL1 (Fig. 6b, c).

\section{Discussion}

EBNA1 is critical for EBV episome maintenance and latent gene expression and provides a selection advantage to EBV positive tumors. We previously described the fragmentbased development of EBNA1 inhibitors that block the DNA binding activity as demonstrated in Chromatin Immunoprecipitation (ChIP) assays and EBNA1-dependent replication assays $[18,19]$. We demonstrated that EBNA1 inhibitors have in vivo activity in B cell lymphoma and several NPC b

\section{YCCEL1}


d

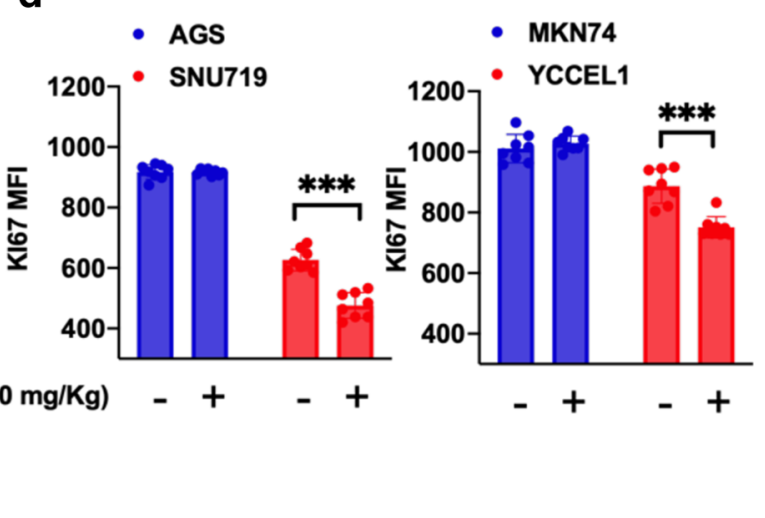

miRNA exon 5 (BART Ex5) in YCCEL1 xenografts. c EBV viral loads in SNU719 and YCCEL1 tumor material from animals treated with VK-1727 or vehicle (student $t$ test; ${ }^{*} p<0.05$, ** $p<0.01$ ) d Ki67 expression (mean fluorescence intensity as measured by flow cytometry)

xenograft models. In this study, we sought to extend the applicability of EBNA1 inhibitors to EBV-associated GC xenograft models. We also wanted to demonstrate selectivity by comparing EBV-positive and EBV-negative GC cell lines in vitro and in vivo.

Here, we show that EBNA1 inhibitors significantly reduce the proliferation and tumor growth of EBV-positive cells in vitro and in vivo. Again, these results suggest that EBNA1 inhibitors are both EBV-specific and effective in vivo (Fig. 4b). Similar to previous studies [18], no weight loss or other adverse effects were observed in treated animals, indicating the safety of these compounds in preclinical models (Fig. 4d). EBNA1 inhibitors appear to be cytostatic in that tumors do not regress after initiation of 


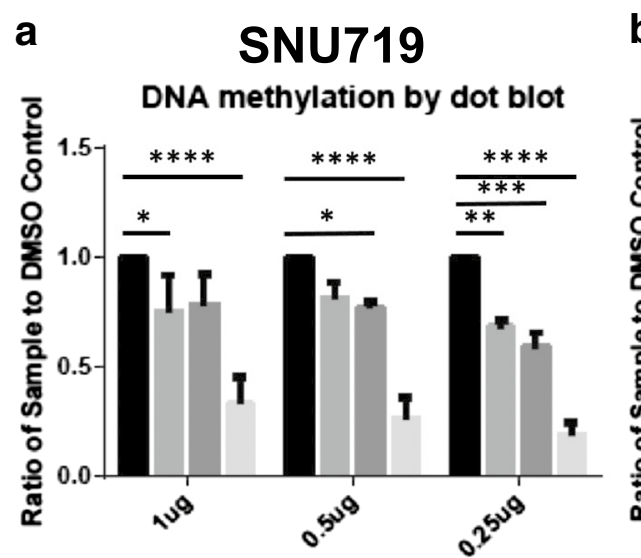

C

SNU719 b

\section{YCCEL1}

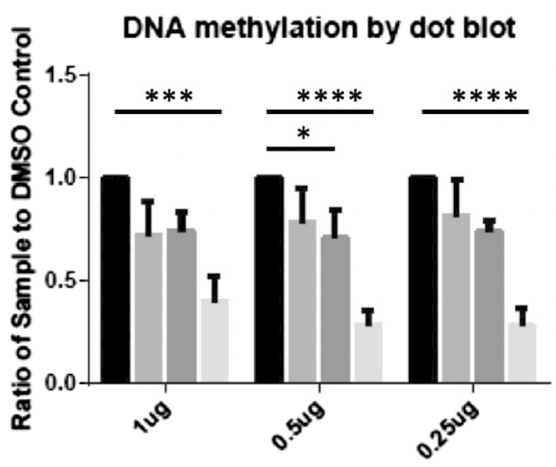

DNA amount

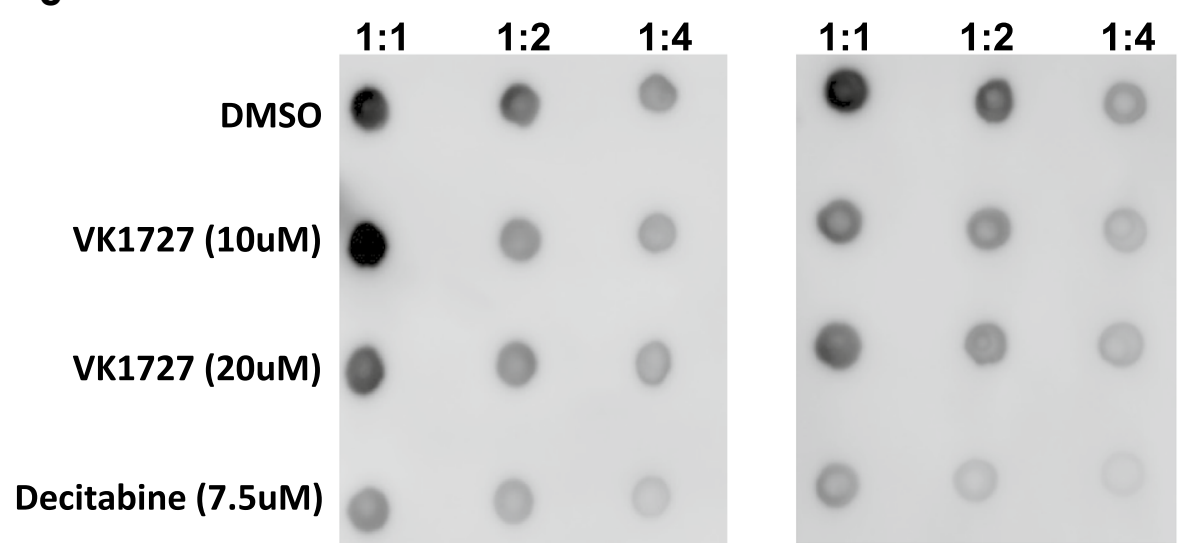

Fig. 6 DNA demethylation in YCCEL1 and SNU719 cells treated with EBNA1 inhibitors. a Quantification of DNA methylation by dot blot in SNU719 represented as ratio compared to DMSO control. b Quantification of DNA methylation by dot blot in YCCEL1

treatment in immunocompromised mouse models and we have not observed clear evidence of apoptosis in treated cells (e.g. no increase in the $<$ G1 population by cell cycle analysis).

We also demonstrate that EBNA1 inhibitors selective inhibit the growth of EBV-positive, but not EBV-negative cells. Previously, we demonstrated that EBNA1 does not affect the growth of the EBV-negative lung carcinoma cell line A549 [18]. We now extend these studies to the EBVnegative GC lines AGS and MKN74. EBNA1 has structural similarities with other viral proteins (LANA from KSHV, E2 from HPV), but not other proteins in the human proteome [22]. Therefore, we would not expect EBNA1 inhibitors to be associated with any on-target toxicities. One limitation of our study is that the EBV-positive/negative GC lines used here do not have the same genetic background. Therefore, selectivity may be idiosyncratic in this limited study with four GC cell lines. represented as ratio compared to DMSO control (Dunnett's multiple comparisons test 2-way ANOVA; $* p<0.05$; $* *<<0.01$; ***p $<$ $0.001 ; * * * * p<0.0001)$. c Representative dot blots for SNU719 and YCCEL1

Treatment with EBNA1 inhibitors significantly decreases the expression of viral genes and EBV viral load in vivo. This observation is consistent with previous observations in in vivo models of NPC and B cell lymphomas. Expression levels of EBNA1, EBER1 and EBER2 are significantly reduced compared to vehicle controls in EBV-positive GC tumors from animals treated with VK-1727 at $10 \mathrm{mg} / \mathrm{kg}$, twice per day. These results are expected given the critical role EBNA1 plays in the replication and maintenance of EBV. Of interest, decreased EBV expression is not observed during short-term $(72 \mathrm{~h})$ treatment of EBV-positive GC cells in culture, which may either indicate that prolonged, consistent application of drug is required to decrease viral gene expression or may suggest differential responses of these tumors in vivo, within the tumor microenvironment. In addition, the short-term effects of viral mRNA expression were different in EBV-positive LCLs compared to EBV-positive GC or EBV-positive NPC cells, suggesting 
the initial effects of EBNA1 inhibition on viral and cellular gene expression may differ in EBV positive cells of different origin. Co-treatment of VK-1727 with GCV did not result in further decreases in cell proliferation, suggesting that there is VK-1727 does not induce full lytic activation in EBVaGC early in response to treatment with EBNA1 inhibitors (Fig. 3b). In addition, EBNA1 inhibitors caused a slight reduction in levels of DNA methylation, suggesting that DNA demethylation may correlate with EBNA1 inhibition and tumor growth suppression in these EBVaGC models.

We previously performed gene expression analysis using the PanCancer Pathways Panel of 700 human genes supplemented with an analysis of $\sim 30 \mathrm{EBV}$ expressed genes in tumors from animals engrafted with an EBV-positive NPCPDX [18]. In those studies, we demonstrated that expression levels from EBV-encoded genes, including EBNA1, EBNA2, LMP1, and ZTA were significantly lower in tumors treated with an EBNA1 inhibitor. Cellular gene pathways for the cell cycle, PI3K, chromosomal modifications, TGF- $\beta$, STAT, RAS, NOTCH and MAPK were also significantly affected by EBNA1 inhibitor treatment. The PI3K/AKT pathway is of particular interest because it is induced by EBV-latent membrane proteins 1 and 2A (LMP1 and LMP2A) and is thought to play an important role in EBV-induced malignancies by affecting cell survival, apoptosis, proliferation, and genomic instability [23]. It has also been suggested that the activation of the PI3K/Akt pathway can result in drug resistance to chemotherapy [23]. In addition, recent studies have indicated that the expression of the AT-rich interaction domain 1A (ARID1A) and phosphatidylinositol4,5-bisphosphate 3-kinase catalytic subunit $\alpha$ (PIK3CA) are associated with the depth of invasion of gastric cancer [24]. Therefore, effective treatment of EBVaGCs is likely to be enhanced by combining EBNA1 inhibitors with inhibitors of other perturbed pathways (e.g. Idelalisib, a PI3K inhibitor that we have shown has activity against EBV-positive NPC tumors in vivo [18]) or ubiquitin conjugation inhibitors. In the future, we anticipate that combining EBNA1 inhibitors with inhibitors of other perturbed pathways may reveal functional crosstalk useful for developing a rationale for combinatorial therapies.

Collectively, these results suggest that pharmacological inhibition of EBNA1 has profound effects on EBV and cellular gene expression, correlating with suppression in EBVdriven tumor cell growth. EBNA1 is essential in promoting the continued proliferative capacity of latently infected cells. Our study demonstrates that EBNA1 inhibitors selectively suppress proliferation of EBV-driven tumor cells. This study may provide a rationale for the use EBNA1 inhibitors as a therapeutic option for patients with EBV-associated GC.

Supplementary Information The online version contains supplementary material available at https://doi.org/10.1007/s10120-021-01193-6.
Acknowledgements We thank Frederick Kenney from The Wistar Imaging Facility for assistance with microscopy and the IVIS. We thank Jeffrey Faust and John Fundyga for sorting GFP-positive cells. The following research Grants from NIH also supported this work S10OD021669-01A1 (Instrumentation grant for the IVIS Spectrum CT), NIH R01-CA093606 and R01-DE017336 to PML, R01-AI130209 to IT and an NCI Cancer Center Support Grant Cancer Center Support Grant P30-CA010815 (Altieri). B.E.G. is supported by a Burroughs Wellcome Fund Career Award in Medical Sciences and NIH R01-AI137337 and R01-CA228700.

Author contributions Conceptualization: SSS, PML, TE, IT, BEG; Methodology: SSS, EMA, DMF, YZ, LBC, YW, JSD; Analysis: SSS, EMA, DMF, YZ, JSD, PML, TEM, YW, BEG; Writing — original draft preparation, review and editing: SSS, PML, TEM; Funding acquisition: PML, TEM; Resources and Supervision: BEG, IT, PML.

\section{Declarations}

Conflict of interest This work was partially funded through a sponsored research agreement with Cullinan Apollo. The Wistar Institute on behalf of the authors T.E.M. and P.M.L. have filed patents covering composition of matter and their use on the small molecules disclosed here for the treatment of human cancer and other diseases (patent number WO2015073864, "EBNA1 Inhibitors and Their Method of Use"; WO2016183534, "EBNA1 Inhibitors and Methods using Same"). P.M.L. has an ownership interest in Vironika, LLC.

\section{Reference}

1. Ferlay J, Soerjomataram I, Dikshit R, Eser S, Mathers C, Rebelo $\mathrm{M}$, et al. Cancer incidence and mortality worldwide: sources, methods and major patterns in GLOBOCAN 2012. Int J Cancer. 2015;136(5):E359-86. https://doi.org/10.1002/ijc.29210 (Epub 2014/09/16 PubMed PMID: 25220842).

2. Shibata D, Weiss LM. Epstein-Barr virus-associated gastric adenocarcinoma. Am J Pathol. 1992;140(4):769-74 (Epub 1992/04/01. PubMed PMID: 1314023; PubMed Central PMCID: PMCPMC1886378).

3. Camargo MC, Kim WH, Chiaravalli AM, Kim KM, Corvalan AH, Matsuo K, et al. Improved survival of gastric cancer with tumour Epstein-Barr virus positivity: an international pooled analysis. Gut. 2014;63(2):236-43. https://doi.org/10.1136/gutjnl-2013304531 (Epub 2013/04/13 PubMed PMID: 23580779; PubMed Central PMCID: PMCPMC4384434).

4. Young LS, Yap LF, Murray PG. Epstein-Barr virus: more than 50 years old and still providing surprises. Nat Rev Cancer. 2016;16(12):789-802. https://doi.org/10.1038/nrc.2016.92 (Epub 2016/11/04 PubMed PMID: 27687982).

5. Imai S, Koizumi S, Sugiura M, Tokunaga M, Uemura Y, Yamamoto N, et al. Gastric carcinoma: monoclonal epithelial malignant cells expressing Epstein-Barr virus latent infection protein. Proc Natl Acad Sci. 1994;91(19):9131. https://doi.org/10.1073/pnas. 91.19.9131.

6. Ott G, Kirchner T, Muller-Hermelink HK. Monoclonal EpsteinBarr virus genomes but lack of EBV-related protein expression in different types of gastric carcinoma. Histopathology. 1994;25(4):323-9. https://doi.org/10.1111/j.1365-2559.1994. tb01350.x (Epub 1994/10/01 PubMed PMID: 7835837).

7. Fukayama M, Ushiku T. Epstein-Barr virus-associated gastric carcinoma. Pathol Res Pract. 2011;207(9):529-37. https://doi.org/ 10.1016/j.prp.2011.07.004 (Epub 2011/09/29 PubMed PMID: 21944426). 
8. Oda K, Tamaru J, Takenouchi T, Mikata A, Nunomura M, Saitoh N, et al. Association of Epstein-Barr virus with gastric carcinoma with lymphoid stroma. Am J Pathol. 1993;143(4):1063-71 (Epub 1993/10/01. PubMed PMID: 8214002; PubMed Central PMCID: PMCPMC1887057).

9. Farrell PJ. Epstein-Barr virus and cancer. Annu Rev Pathol. 2019;14:29-53. https://doi.org/10.1146/annurev-pathmechdis012418-013023 (Epub 2018/08/21 PubMed PMID: 30125149).

10. Frappier L. EBNA1. Curr Top Microbiol Immunol. 2015;391:334. https://doi.org/10.1007/978-3-319-22834-1_1 (Epub 2015/10/03 PubMed PMID: 26428370).

11. Yin Q, Flemington EK. siRNAs against the Epstein Barr virus latency replication factor, EBNA1, inhibit its function and growth of EBV-dependent tumor cells. Virology. 2006;346(2):385-93. https://doi.org/10.1016/j.virol.2005.11. (021 Epub 2005/12/14 PubMed PMID: 16343579).

12. Wang J, Liang C, Meng F, Xu X, Wu Y, Lu L. Lentivirus-mediated RNA interference targeting EBNA1 gene inhibits the growth of GT-38 cells in vitro and in vivo. Oncol Lett. 2019;18(3):2286-91. https://doi.org/10.3892/ol.2019.10543 (Epub 2019/06/28 PubMed PMID: 31402935).

13. Dheekollu J, Malecka K, Wiedmer A, Delecluse HJ, Chiang AK, Altieri DC, et al. Carcinoma-risk variant of EBNA1 deregulates Epstein-Barr virus episomal latency. Oncotarget. 2017;8(5):724864. https://doi.org/10.18632/oncotarget.14540 (Epub 2017/01/13 PubMed PMID: 28077791; PubMed Central PMCID: PMCPMC5352318).

14. Frappier L. Contributions of Epstein-Barr nuclear antigen 1 (EBNA1) to cell immortalization and survival. Viruses. 2012;4(9):1537-47. https://doi.org/10.3390/v4091537 (Epub 2012/11/22 PubMed PMID: 23170171; PubMed Central PMCID: PMCPMC3499818)

15. Lu J, Murakami M, Verma SC, Cai Q, Haldar S, Kaul R, et al. Epstein-Barr Virus nuclear antigen 1 (EBNA1) confers resistance to apoptosis in EBV-positive B-lymphoma cells through up-regulation of survivin. Virology. 2011;410(1):64-75. https://doi.org/ 10.1016/j.virol.2010.10.029 (Epub 2010/11/26 PubMed PMID: 21093004; PubMed Central PMCID: PMCPMC4287362).

16. Sivachandran N, Dawson CW, Young LS, Liu FF, Middeldorp J, Frappier L. Contributions of the Epstein-Barr virus EBNA1 protein to gastric carcinoma. J Virol. 2012;86(1):60-8. https://doi. org/10.1128/jvi.05623-11 (Epub 2011/10/21 PubMed PMID: 22013060; PubMed Central PMCID: PMCPMC3255905).

17. Lu F, Tempera I, Lee HT, Dewispelaere K, Lieberman PM. EBNA1 binding and epigenetic regulation of gastrokine tumor suppressor genes in gastric carcinoma cells. Virol J. 2014;11:12. https://doi.org/10.1186/1743-422x-11-12 (Epub 2014/01/28
PubMed PMID: 24460791; PubMed Central PMCID: PMCPMC3904692).

18. Messick TE, Smith GR, Soldan SS, McDonnell ME, Deakyne JS, Malecka KA, et al. Structure-based design of small-molecule inhibitors of EBNA1 DNA binding blocks Epstein-Barr virus latent infection and tumor growth. Sci Transl Med. 2019. https://doi.org/10.1126/scitranslmed.aau5612 (Epub 2019/03/08 PubMed PMID: 30842315; PubMed Central PMCID: PMCPMC6936217).

19. Messick TE, Tolvinski L, Zartler ER, Moberg A, Frostell Å, Smith GR, et al. Biophysical screens identify fragments that bind to the viral DNA-binding proteins EBNA1 and LANA. Molecules. 2020. https://doi.org/10.3390/molecules25071760 (Epub 2020/04/16 PubMed PMID: 32290261; PubMed Central PMCID: PMCPMC7180839).

20. Oh ST, Seo JS, Moon UY, Kang KH, Shin DJ, Yoon SK, et al. A naturally derived gastric cancer cell line shows latency I Epstein-Barr virus infection closely resembling EBV-associated gastric cancer. Virology. 2004;320(2):330-6. https://doi.org/10. 1016/j.virol.2003.12.005 (Epub 2004/03/16 PubMed PMID: 15016554).

21. Kim DN, Seo MK, Choi H, Kim SY, Shin HJ, Yoon AR, et al. Characterization of naturally Epstein-Barr virus-infected gastric carcinoma cell line YCCEL1. J Gen Virol. 2013;94(Pt 3):497506. https://doi.org/10.1099/vir.0.045237-0 (Epub 2012/11/24 PubMed PMID: 23175241).

22. De Leo A, Calderon A, Lieberman PM. Control of viral latency by episome maintenance proteins. Trends Microbiol. 2020;28(2):150-62. https://doi.org/10.1016/j.tim.2019.09.002 (Epub 2012/11/24 PubMed PMID: 31624007; PubMed Central PMCID: PMCPMC6980450).

23. Chen J. Roles of the PI3K/Akt pathway in Epstein-Barr virusinduced cancers and therapeutic implications. World J Virol. 2012;1(6):154-61. https://doi.org/10.5501/wjv.v1.i6.154 (Epub 2013/11/01 PubMed PMID: 24175221; PubMed Central PMCID: PMCPMC3782276).

24. Zhou H, Tan S, Li H, Lin X. Expression and significance of EBV, ARID1A and PIK3CA in gastric carcinoma. Mol Med Rep. 2019;19(3):2125-36. https://doi.org/10.3892/mmr.2019.9886 (Epub 2019/02/13 PubMed PMID: 30747208; PubMed Central PMCID: PMCPMC6390055).

Publisher's Note Springer Nature remains neutral with regard to jurisdictional claims in published maps and institutional affiliations. 